\title{
OPTIMALISASI PENGUKURAN ARUS OLEH CURRENT TRANSFORMER UNTUK MEMINIMALISIR SUSUT ENERGI PADA PABRIK BAJA PT. INTI GENERAL YAJA STEEL DAERAH SEMARANG BARAT
}

\author{
Devita Amalia, Eko Ariyanto \\ Program Studi Diploma III Teknik Elektro \\ Fakultas Teknik Universitas Diponegoro
}

\begin{abstract}
kWhmeter adalah suatu alat ukur energi listrik yang mengukur secara langsung hasil kali tegangan, arus, faktor kerja, dan waktu yang bekerja selama jangka waktu tertentu. Pengukuran energi yang dominan adalah pengukuran arus, di mana arus yang diukur melebihi arus yang terdapat di kWh meter. Untuk itu dibutuhkan suatu peralatan instrumen yang dapat menurunkan arus yaitu trafo arus.

Susut distribusi pada sistem kelistrikan dapat terjadi pada alat pengukur dan pembatas (APP) yang dipergunakan dalam transaksi tenaga listrik dengan pelanggan. Susut yang terjadi pada APP ditentukan oleh akurasi APP dan akurasi pembacaan atau pengambilan data hasil pengukuran.

Untuk menghindari atau mengurangi susut tersebut pemilihan trafo arus yang tepat sangat dibutuhkan seperti mengamati seberapa besar ketelitian trafo arus dalam pengukuran. Kelas ketelitian trafo arus, burden, kesalahan sudut, dan juga arus nominal dari sisi primer trafo arus harus diperhatikan. Jika pemilihan tidak sesuai, maka akan memungkinkan terjadinya susut.
\end{abstract}

Kata kunci : Susut, APP, Trafo Arus.

\section{PENDAHULUAN}

Susut distribusi pada sistem kelistrikan dapat terjadi pada jaringan dan alat pengukur dan pembatas (APP) yang dipergunakan dalam transaksi tenaga listrik dengan pelanggan. Susut yang terjadi pada APP ditentukan oleh

- Akurasi APP seperti rasio, kelas akurasi, dan burden trafo arus maupun trafo tegangan, kualitas dan kelas akurasi meter energi yang mampu mengukur besaran listrik dengan benar dan mempunyai fitur sesuai kebutuhan.

- Akurasi pembacaan atau pengambilan data hasil pengukuran biasanya bersangkutan dengan kesalahan manusia (human error).

\section{Batasan Masalah}

Penelitian dibatasi pada perlengkapan Alat Ukur dan Pembatas (APP) yang tidak sesuai standar khususnya CT (current transformer) / trafo arus pada pelanggan besar dalam sisi pengukuran dan hanya membahas tentang rasio CT serta kesalahan arus.

\section{LANDASAN TEORI}

Pada dasarnya prinsip kerja transformator arus sama dengan transformator daya atau tenaga. Jika pada kumparan primer mengalir arus $\mathrm{I}_{1}$, maka pada kumparan primer timbul gaya gerak magnet sebesar $\mathrm{N}_{1} \mathrm{I}_{1}$. Gaya gerak magnet ini memproduksi fluks pada inti, kemudian membangkitkan gaya gerak listrik (GGL) pada kumparan sekunder. Jika terminal kumparan sekunder tertutup, maka pada kumparan sekunder mengalir arus $\mathrm{I}_{2}$, arus ini menimbulkan gaya gerak magnet $\mathrm{N}_{2} \mathrm{I}_{2}$ pada kumparan sekunder.

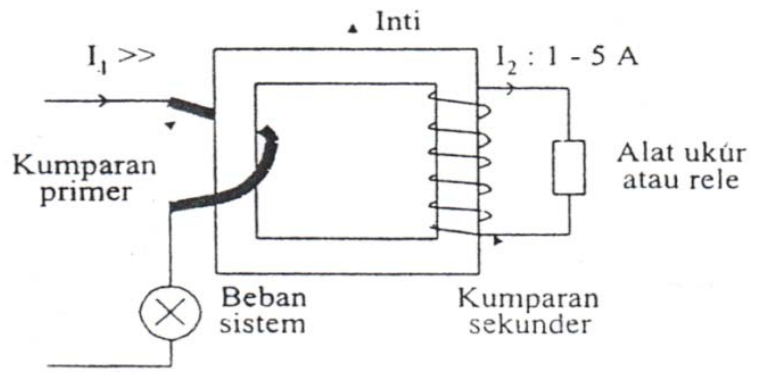

Gambar 1. Konstruksi Trafo Arus

Definis-Definisi Trafo Arus

Kesalahan Transformator (Transformasi eror)

Kesalahan transformator adalah perbandingan antara arus primer dan arus sekunder.

$$
K n=\frac{I p}{I s}
$$

Di mana

$\mathrm{Kn} \quad$ : perbandingan transformasi

Ip : arus pengenal transformasi

Is : arus pengenal sekunder

Kesalahan Arus Transformator (Current Transformer error)

Kesalahan arus transformator adalah kesalahan suatu transformator pada pengukuran arus yang muncul dari kenyataan bahwa rasio transformasi aktual tidak sama dengan rasio transformasi pengenal. Suatu alat semakin teliti jika kesalahan arusnya kecil.

$$
\varepsilon \%=\frac{K n \times I s-I p}{I p} \times 100 \%
$$


Keterangan :

$$
\begin{array}{ll}
\mathrm{Kn} & : \text { perbandingan transformator } \\
\varepsilon & : \text { kesalahan arus (\%) } \\
\text { Is } & : \text { arus sekunder sebenarnya (Amp) } \\
\text { Ip } & : \text { arus primer sebenarnya (Amp) }
\end{array}
$$

Karena adanya perbedaan antara arus yang masuk di sisi primer dengan arus yang terbaca di sisi sekunder, dapat menimbulkan perbedaan transformasi arus yang sebenarnya dengan kenyataannya. Bila CT dipergunakan untuk pengukuran energi ( $\mathrm{kW}$ meter), kesalahan arus ini sangat berpengaruh terhadap pengukuran energi tersebut.

\section{Kelas Akurasi}

Kelas akurasi adalah arus pada trafo arus yang dibatasi oleh kesalahan arus dan kesalahan fasa. Standar kelas akurasi yang dipergunakan untuk pengukuran seperti terlihat dalam tabel di bawah ini.

- Untuk kelas 0,1;0,2 ; 0,5 dan 1, pada frekuensi pengenal kesalahan arus dan pergeseran fasa tidak melebihi dari nilai yang ditentukan seperti terlihat dalam tabel 2.1, burden sekunder antara 25\% sampai dengan $100 \%$ dari burden (kemampuan trafo dibebani) pengenal.

\begin{tabular}{|c|c|c|c|c|c|c|c|c|}
\hline \multirow[t]{2}{*}{$\begin{array}{l}\text { Klas } \\
\text { kete } \\
\text { litia } \\
\text { n }\end{array}$} & \multicolumn{4}{|c|}{$\begin{array}{c}\text { +/- } \% \text { kesalahan rasio } \\
\text { arus pada } \% \text { dari } \\
\text { arus pengenal }\end{array}$} & \multicolumn{4}{|c|}{$\begin{array}{c}/- \text { pergeseran fase } \\
\text { pada } \\
\% \text { dari arus } \\
\text { pengenal } \\
\text { menit ( } 1 / 60 \text { derajat })\end{array}$} \\
\hline & 5 & 20 & $\begin{array}{c}10 \\
0\end{array}$ & $\begin{array}{c}12 \\
0\end{array}$ & 5 & 20 & $\begin{array}{c}10 \\
0\end{array}$ & $\begin{array}{c}12 \\
0\end{array}$ \\
\hline 0,1 & 0,4 & 0,2 & 0,1 & 0,1 & 15 & 8 & 5 & 5 \\
\hline 0,2 & 0,75 & 0,35 & 0,2 & 0,2 & 30 & 15 & 10 & 10 \\
\hline 0,5 & 1,5 & 0,75 & 0,5 & 0,5 & 90 & 45 & 30 & 30 \\
\hline 1 & 3 & 1,5 & 1 & 1 & 180 & 90 & 60 & 60 \\
\hline
\end{tabular}

Tabel 1. Batas Kesalahan Arus dan Kesalahan Sudut Untuk Kelas 0,1-1,0 Sesuai IEC 60044-1

- Untuk kelas 0,2s dan 0,5s, dipergunakan untuk aplikasi khusus untuk kWh meter yang mana pengukuran yang tepat pada arus antara 50 mA sampai dengan 6 A. Kesalahan arus dari pergeseran fasa, tidak melebihi dari nilai yang ditentukan seperti terlihat pada tabel 2.2, bila burden sekunder antara $25 \%$ sampai dengan $100 \%$ dari burden pengenal. Pemakaian kelas

\begin{tabular}{|c|c|c|c|c|c|c|c|c|c|c|}
\hline \multicolumn{6}{|c|}{ Keperluan Khusus } & \multicolumn{5}{|c|}{ 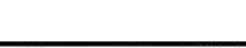 } \\
\hline \multirow[t]{2}{*}{$\begin{array}{c}\text { Kelas } \\
\text { Reteli } \\
\text { tian }\end{array}$} & \multicolumn{5}{|c|}{$\begin{array}{l}\text { \$1-\% kesalahan ratio arus } \\
\text { pada \% dari arus pengenal }\end{array}$} & \multicolumn{5}{|c|}{$\begin{array}{l}1 . \% \text { pergeseran fase pada \% dari } \\
\text { anus pengenal, menit } \\
\text { (centradians)) }\end{array}$} \\
\hline & & 5 & 20 & 100 & 120 & 1 & 5 & 20 & 100 & 120 \\
\hline$\overline{0,25^{* *}}$ & $\overline{0,75}$ & $\overline{0,35}$ & $\overline{0,2}$ & $\overline{0,2}$ & $\overline{0,2}$ & 30 & $\overline{15}$ & 10 & 10 & 10 \\
\hline$\overline{0,5 S^{* *}}$ & 1,5 & $\overline{0,75}$ & 0,5 & 0,5 & 0,5 & 90 & $\overline{45}$ & 30 & 30 & 30 \\
\hline
\end{tabular}
ini diutamakan pada rasio 25/5, 50/5, 100/5 dengan arus pengenal 5 Ampere.

Tabel 2. Batas Kesalahan Untuk CT
- Untuk kelas 3 dan 5, kesalahan arus dari pergeseran fasa tidak melebihi dari nilai yang ditentukan seperti terlihat pada tabel 2.3, bila burden sekunder antara 50\% sampai dengan 100\% dari burden pengenalnya.

Tabel 3. Batas Kesalahan Untuk Kelas 3 dan 5 Sesuai IEC 60044-1

\begin{tabular}{|c|c|c|c|}
\hline $\begin{array}{c}\text { Kelas } \\
\text { ketelitian }\end{array}$ & \multicolumn{2}{|c|}{$\begin{array}{c}+/-\% \text { kesalahan ratio arus } \\
\text { pada \% dari arus pengenal }\end{array}$} & \multirow{2}{*}{ Pemakaian } \\
\cline { 2 - 3 } & $\mathbf{5 0}$ & 100 & \\
\hline 3 & 3 & 3 & instruments \\
\hline 5 & 5 & 5 & instruments \\
\hline
\end{tabular}

Keterangan :

* $\quad$ : untuk laboratorium

** : untuk precision revenue metering

*> $\quad$ : untuk standard metering

\section{PEMBAHASAN}

Berdasarkan data yang didapat di lapangan, pemakaian beban sehari di PT. Inti General Yaja Steel II adalah 65\%. Dengan menggunakan pemakaian beban yang sama yaitu 65\%, kemudian bandingkan antara CT yang menggunakan rasio 300/5 dengan 200/5.

\section{Menggunakan rasio CT 300/5}

Daya kontrak $=6000 \mathrm{kVA}$

Tegangan $=20 \mathrm{kV}$

Rasio = 300/5

Arus nominal (In) $\quad=173 \mathrm{~A}$

Pemakaian beban $=65 \%$

Maka pemakaian arus sebenarnya di sisi primer Ip sebenarnya $=$ pemakaian beban $\mathrm{x}$ In

Ip sebenarnya $=65 \% \times 173$

Ip sebenarnya $=112,45 \mathrm{~A}$

Untuk mencari kerugian CT, terlebih dahulu mencari penyesuaian eror yang boleh terjadi.

Penyesuaian eror \%

$=$ pemakaian beban $\mathrm{x} \frac{\text { In }}{\text { Ip pengenal }}$

Penyesuaian eror $\%=65 \% \times \frac{173}{300}$

Penyesuaian eror $\%=65 \% \mathrm{x} 0,58$

Penyesuaian eror $\%=38 \%$,

jadi kerugian CT-nya adalah sekitar -0,731\%

Sedangkan arus sekunder yang digunakan adalah

$\varepsilon=\frac{\mathrm{Kn} \times \mathrm{Is}-\mathrm{Ip}}{\mathrm{Ip}} \times 100 \%$

$\varepsilon=\frac{\mathrm{Kn} \times \mathrm{Is}-\mathrm{Ip}}{\mathrm{Ip}} \times 100 \%$

$-0,731 \%=\frac{60 \times \text { Is }-112,45}{112,45} \times 100 \%$

Is $=\frac{-0,00731 \times 112,45+112,45}{60}$

Is $=1,86 \mathrm{~A}$ 
Padahal arus sekunder yang sebenarnya mengalir di dalam CT ,

$\frac{\mathrm{Ip}}{\mathrm{Is}}=\frac{\mathrm{Ips}}{\mathrm{Iss}}$

Is sebenarnya $=\frac{112,45 \times 5}{300}$

Is sebenarnya $=1.87 \mathrm{~A}$

Ternyata dalam proses penyaluran beban, ada beberapa arus yang hilang. Besar arus yang dikirim dari distribusi melalui jaringan dan yang seharusnya didapat oleh pelanggan, tidak sama dengan kenyataan arus yang diterima pelanggan tersebut. Hal ini disebabkan, di dalam trafo arus terdapat kebocaran arus (rugi-rugi), sehingga tidak ada trafo yang ideal.

Selisih antara trafro arus di sisi primer maupun sekunder,

- Pada sisi sekunder

Selisih arus sekunder

$=$ Is seharusnya - Is kenyataan

$=1,87-1,86=0,01 \mathrm{~A}$

- $\quad$ Pada sisi primer

Selisih arus primer

$=$ selisih arus sekunder $\mathrm{x} \mathrm{Kn}$

$=0,01 \times 60=0,6 \mathrm{~A}$

Diketahui pemakaian sehari adalah 24 jam dalam 30 hari. Faktor daya yang dipakai oleh pelanggan tersebut maksimal adalah 0,967 (Lihat dari data load profile). Kerugian energi pada CT adalah

Kerugian energi $=$

$\sqrt{3} \times V \times$ selisih primer $\times 24 \times \cos \theta \times 30$

Kerugian energi

$=\sqrt{3} \times 20 \times 0,6 \times 24 \times 0,967 \times 30$

Kerugian energi $=14.471 \mathrm{kWh} /$ bulan

Biaya pemakaian pada pelanggan tersebut sesuai dengan tarif dasar listrik yaitu $704 \mathrm{Rp} / \mathrm{kWh}$. Maka kerugian PLN sesuai dengan penggunaan tiga buah CT 300/5, yaitu :

Kerugian PLN $=$ kerugian energi $\mathrm{x}$ biaya pemakaian

$$
=14.471 \times 704
$$

= Rp 10.187.584,- per bulan

\section{Menggunakan rasio CT 200/5}

$\begin{array}{ll}\text { Daya kontrak } & =6000 \mathrm{kVA} \\ \begin{array}{ll}\text { Tegangan } & =20 \mathrm{kV} \\ \text { Rasio } & =200 / 5\end{array}\end{array}$

Arus nominal (In) $\quad=173 \mathrm{~A}$

Pemakaian beban $=65 \%$

Pemakaian arus sebenarnya di sisi primer, Ip sebenarnya $=$ pemakaian beban $\mathrm{x}$ In Ip sebenarnya $=65 \% \times 173$ Ip sebenarnya $=112,45 \mathrm{~A}$
Untuk mencari kerugian CT, terlebih dahulu mencari penyesuaian eror yang boleh terjadi Penyesuaian eror \%

$=$ pemakaian beban $\mathrm{x} \frac{\mathrm{In}}{\text { Ip pengenal }}$

Penyesuaian eror $\%=65 \% \times \frac{173}{200}$

Penyesuaian eror $\%=65 \% \times 0,87$

Penyesuaian eror $\%=56,55 \%$, jadi kerugian CT-nya sekitar $\mathbf{- 0 , 7 1 2 \%}$

Sedangkan arus sekunder yang digunakan, $\varepsilon=\frac{\text { Kn } x \text { Is }- \text { Ip }}{\text { Ip }} \times 100 \%$

$\varepsilon=\frac{\mathrm{Kn} \times \mathrm{Is}-\mathrm{Ip}}{\mathrm{Ip}} \times 100 \%$

$-0,712 \%=\frac{40 \times \text { Is }-112,45}{112,45} \times 100 \%$

Is $=\frac{-0,00712 \times 112,45+112,45}{40}$

Is $=2,79 \mathrm{~A}$

Padahal arus yang sebenarnya mengalir di dalam CT tersebut,

$\frac{\mathrm{Ip}}{\mathrm{Is}}=\frac{\mathrm{Ips}}{\mathrm{IsS}}$

Is sebenarnya $=\frac{112,45 \times 5}{200}$

Is sebenarnya $=2,80 \mathrm{~A}$

Selisih antara trafro arus di sisi primer maupun sekunder

- Pada sisi sekunder

Selisih arus sekunder

$=$ Is sebenarnya - Is kenyataan

$=2,80-2,79=0,01 \mathrm{~A}$

- $\quad$ Pada sisi primer

Selisih arus primer

$=$ selisih arus sekunder $\mathrm{x} \mathrm{Kn}$

$=0,01 \times 40=0,4 \mathrm{~A}$

Diketahui pemakaian sehari adalah 24 jam dalam 30 hari. Faktor daya yang dipakai oleh pelanggan tersebut maksimal 0,967 (Lihat tabel 4.3), sehingga kerugian energi pada CT tersebut,

Kerugian energi $=$

$\sqrt{3} \times \mathrm{V} \times$ selisih primer $\times 24 \times \cos \theta \times 30$

Kerugian energi

$=\sqrt{3} \times 20 \times 0,4 \times 24 \times 0,967 \times 30$

Kerugian energi $=9.647 \mathrm{kWh} /$ bulan

Biaya pemakaian pada pelanggan tersebut sesuai dengan tarif dasar listrik yaitu $704 \mathrm{Rp} / \mathrm{kWh}$. Maka Kerugian PLN sesuai dengan penggunaan tiga buah CT 200/5, yaitu

Kerugian PLN = kerugian energi $\mathrm{x}$ biaya pemakaian

$$
=9.647 \times 704
$$

= Rp 6.791.488 per bulan 
Jadi selisih kerugian antara menggunakan CT 300/5 dengan 200/5 yang didapat dengan pemakaian $65 \%$ adalah

- Kerugian PT.PLN (Persero)

Rp.10.187.584 - Rp.6.791.488 =

Rp.3.396.096,-

- kerugian energi

$14.471-9.647=4.824 \mathrm{kWh} / \mathrm{bulan}$

- selisih kerugian CT (error CT)

$-0,731 \%+0,712 \%=-0,019 \%$.

Dari perbandingan ini didapat, dengan pemakaian beban yang sama, ternyata rasio 300/5 kerugian CT-nya lebih tinggi dibandingkan dengan 200/5. Kerugian CT dapat menyebabkan kesalahan dalam pengukuran karena error pada CT besar. Kerugian bagi pihak PT. PLN (Persero) juga besar karena energi yang hilang lebih banyak.

\section{PENUTUP}

\section{Kesimpulan}

- Rasio arus yang terpasang di lapangan ternyata tidak sesuai dengan daya kontrak pelanggan dengan PT.PLN (Persero). Hal ini menyebabkan susut energi seperti arus bocor semakin banyak, energi yang hilang semakin banyak dan erornya besar.

- Pemakaian beban yang sama, ternyata rasio 300/5 kerugian CT-nya lebih tinggi dibandingkan dengan 200/5. Kerugian CT dapat menyebabkan kesalahan dalam pengukuran dan menyebabkan kerugian bagi pihak PT.PLN (Persero). Semakin besar erornya, semakin besar kerugian yang dihasilkan baik energi yang hilang maupun bagi pendapatan PT.PLN(Persero) serta ketelitian pengukuran arusnya rendah.

- Pemilihan perlengkapan APP yang tepat sangat penting, karena tidak tepatnya dalam memilih perlengkapan APP dapat menyebabkan susut.

\section{Saran} diharapkan :

Dari kesimpulan hasil pengamatan ini

1) Perlu penggantian $C T$ di pelanggan tersebut dari rasio 300/5 menjadi 200/5.

2) PT. PLN (Persero) diharapkan dapat lebih cermat dalam memilih perlengkapan alat ukur khususnya trafo arus (CT) dengan memperhatikan arus nominal maupun kelas ketelitian CT.

\section{DAFTAR PUSTAKA}

1. Kadarisman, Pribadi dan Wahyudi Sarimun, 2009, Current Transformer, [Online] http://gikotapinang.files.wordpress.com/2011/11 /ct.ppt.
2. Managemen APP, 2008, Managemen Alat Pengukur dan Pembatas, Jakarta, PT.PLN (Persero).

3. Sarimun N, Wahyudi, 2011, Proteksi Sistem Distribusi Tenaga Listrik, Depok, Garamond.

4. Sarimun, Wahyudi, 2009, Pengaruh Instrument Pengukuran pada Meter Transaksi Tenaga Listrik,[Online] http://xa.yimg.com/kq/groups/26952859/137743 0094.

5. SPLN D3.014-1, 2009, Trafo Arus, Jakarta, PT. PLN (Persero).

6. SPLN D5.001, 2008, Pedoman Pemilihan Meter Energi, Jakarta, PT.PLN (Persero).

7. Tim Jaya, 2013, Pemeliharaan Trafo Arus (CT) dan Tegangan (PT). [Online]. http://www.scribd.com/doc/82304400/Pemeliha raan-CT-Dan-PT.

8. Tobing, Bonggas L, 2003, Peralatan Tegangan Tinggi, Jakarta, PT. Gramedia Pustaka Utama.

9. Wibowo, Lutfi Lastiko, 2011, Transformator Arus dan Pemeliharaan Transformator Arus pada PT. Pln (Persero) P3b Region Jawa Tengah \& Diy Upt Semarang Gis $150 \mathrm{kv}$ Simpang Lima. [Online]. http://www.elektro.undip.ac.id/el_kpta/wpconte nt/uploads/2012/05/L2F008136_MKP.pdf.

10. Zuhal, 1992, Dasar Teknik Tenaga Listrik dan Elektronika Daya, Jakarta, PT. Gramedia Pustaka Utama.

11. Zuhal, 2004, Prinsip Dasar Elektroteknik, Jakarta, PT. Gramedia Pustaka Utama. 